\title{
EL PENSAMIENTO COMPLEJO Y LA TRANSDISCIPLINARIEDAD: FENÓMENOS EMERGENTES DE UNA NUEVA RACIONALIDAD*
}

\author{
SERGIO NÉSTOR OSORIO GARCÍA** \\ UNIVERSIDAD MILITAR NUEVA GRANADA
}

Recibido/ Received/ Recebido: 18/01/2012 - Aceptado/ Accepted/Aprovado: 17/05/2012

\begin{abstract}
Resumen
Hoy tenemos que aprender a diferenciar y a distinguir, sin tener por ello que separar. En este sentido hay dos pares de conceptos claramente diferenciables y no por ello separables: por un lado, los conceptos complejidad y pensamiento complejo y por otro lado, conocimiento disciplinar (multi-poli e interdisciplinar) y conocimiento transdisciplinar. Para la ciencia clásica el pensamiento complejo y el conocimiento transdisciplinar es un absurdo, pero para éstos, el ideal de racionalidad de la ciencia clásica es necesario y válido, pero insuficiente para comprender la Realidad en el tiempo actual. Se hace necesario un nuevo paradigma de racionalidad que permita pensar la unidad de los conocimientos fragmentados en disciplinas de cara a la supervivencia de la especie humana en esta era que se ha convertido en planetaria. La presente reflexión busca presentar desde las apuestas conceptuales de Edgar Morin (pensamiento complejo) y de Basarab Nicolescu (conocimiento transdisciplinar) la dimensión epistemológica, ontológica y metodológica de la emergencia de esta nueva racionalidad.
\end{abstract}

Palabras clave: complejidad, pensamiento complejo, conocimiento disciplinar, conocimiento transdisciplinar, nueva racionalidad.

\section{COMPLEX THOUGHT AND TRANSDISCIPLINARITY OF EMERGING PHENOMENA OF A NEW RATIONALITY}

\begin{abstract}
Today we have to learn to differentiate and distinguish, without the need of separation. In this sense, there are two pairs of concepts clearly differentiable and not necessarily separable: by one side, complexity and complex thought, and by the other side, disciplinary knowledge (multi-poli and inter-disciplinary) and transdisciplinary knowledge. For classic science, complex thought and transdisciplinary knowledge is absurd, but the ideal of classic science rationality is necessary and valid, but insufficient to comprehend reality in current times. It is necessary a new paradigm of rationality which allows thinking the unit of fragmented knowledge in disciplines related to human species survival in this era which has become planetary. This reflection presents from Edgar Morin's (complex thought) and Basarab Nicolescu's (transdisciplinary knowledge) conceptual proposals, the epistemological, ontological and methodological dimension of the emergence of this new rationality.

Keywords: complexity, complex thinking, knowledge of discipline, knowledge transdisciplinary, new racionality.
\end{abstract}

* Este artículo se elabora en el contexto del proyecto de investigación HUM 950: "La Bioética a la luz de las epistemologías de segundo orden", con la financiación de la Vicerrectoría de Investigaciones de la Universidad Militar Nueva Granada.

** Bioeticista, filósofo, teólogo y educador. Magíster en Bioética y en Programación Neurolingüística, candidato a doctor en teología, Pontificia Universidad Javeriana, Bogotá-Colombia. Docente Facultad de Educación y Humanidades, Universidad Militar Nueva Granada, Bogotá-Colombia. Correos electrónicos: sergio.osorio@unimilitar.edu.co; sergionestorosorio@yahoo.com 


\title{
O PENSAMENTO COMPLEXO E A TRANSDISCIPLINARIDADE: FENÔMENOS EMERGENTES DE UMA NOVA RACIONALIDADE
}

\author{
Resumo
}

\begin{abstract}
Hoje temos que aprender a diferenciar e a distinguir, sem ter que, por isso, separar. Neste sentido há dois pares de conceitos claramente diferenciáveis e não por isso separáveis: por um lado, os conceitos de complexidade e de pensamento complexo e, por outro lado, os conceitos de conhecimento disciplinar (multi-poli e interdisciplinar) e o de conhecimento transdisciplinar. Para a ciência clássica o pensamento complexo e o conhecimento transdisciplinar é um absurdo. Porém, para estes, o ideal de racionalidade da ciência clássica é necessário e válido, mas insuficiente para compreender a realidade atual. Faz-se necessário um novo paradigma de racionalidade que permita pensar a unidade dos conhecimentos fragmentados em disciplinas relacionadas diretamente com a sobrevivência da espécie humana nesta era que se tornou planetária. A presente reflexão procura apresentar, a partir das apostas conceituais de Edgar Morin (pensamento complexo) e de Basarab Nicolescu (conhecimento transdisciplinar), a dimensão epistemológica, ontológica e metodológica da emergência desta nova racionalidade.
\end{abstract}

Palavras chave: complexidade, pensamento complexo, conhecimento disciplinar, conhecimento transdisciplinar, nova racionalidade.

Osorio, N. (2012) El pensamiento complejo y la transdisciplinariedad fenómenos emergentes de una nueva racionalidad. En: Revista de la Facultad de Ciencias Económicas de la Universidad Militar Nueva Granada. rev.fac.cienc.econ, XX (1)

JEL: M19, Z13, Z19.

\section{Introducción}

Hoy estamos viviendo una verdadera revolución paradigmática no sólo en el conocimiento humano, sino también en la manera en que la humanidad como especie puede hacerse viable. El presente artículo quiere mostrar las condiciones epistemológicas de posibilidad para comprender la emergencia de una nueva racionalidad científica, racionalidad que se hace necesaria para continuar haciéndonos viables en un mundo que se ha convertido en planetario.

Las estaciones de tránsito para desarrollar esta reflexión serán las siguientes:

En primer lugar, presentaré la dimensión epistemológica de la nueva racionalidad a la luz de los operadores de pensamiento complejo de Edgar Morin; en segundo lugar -y para tener una mejor comprensión de la emergencia de la nueva racionalidad-, recapitularé el ideal de la racionalidad de la ciencia clásica $y$, en tercer lugar propondré a la luz del conocimiento transdisciplinar de Basarab Nicolescu, las características metodológicas de la nueva racionalidad.

\section{Dimensión epistemológica de una nue- va racionalidad desde los operadores del pensamiento complejo en Edgar Morin}

Edgar Morin es uno de los pensadores contemporáneos que ha centrado su actividad intelectual en la necesidad de dar a luz a un pensamiento complejo capaz de articular los conocimientos fragmentados en disciplinas o campos de saber que si bien nos permiten profundizar en aspectos concretos del conocimiento de la realidad, -al mismo tiempo y luego de dos siglos de implementación-, empiezan a mostrar un nuevo oscurantismo, que no es ya el oscurantismo de la ignorancia, sino el de una racionalidad restringida que permite, sin duda alguna, un avance en profundidad en algún aspecto de la realidad, pero que al mismo tiempo nos incapacita para una comprensión de la complejidad organizada, en donde cada aspecto de la realidad se nos da a lado de otros, y en los que 
éstos pueden alcanzar alguna validez y sentido (Morin, 2010, 81-135).

Morin haciendo alusión a una metáfora arquitectónica, nos dice que su apuesta por un pensamiento complejo se empotra y diferencia a la vez de unos conocimientos a partir de los cuales se ha construido y al mismo tiempo que ha superado. La metáfora arquitectónica para hablarnos del pensamiento complejo es la de una casa de tres pisos.

En el primer piso, es decir a la base estarían, según Morin, las tres grandes teorías contemporáneas: la teoría general de sistemas, la teoría cibernética y la teoría de la información. Estas tres teorías le han permitido pensar en un principio de causalidad no lineal que se expresará en el pensamiento complejo a través del principio de recursividad.

En el segundo piso estarían las teorías de la autoorganización propuestas por la revolución biológica contemporánea y las teorías cibernéticas de autores como Atlan (1990), Capra (2002), Prigogine (1987), Von Neumann (2004), etc. Estas perspectivas conceptuales le permiten a Morin comprender las emergencias globales y las micro-emergencias de toda organización, y todavía más, le permiten comprender como la organización viviente no es la simple suma de muchos componentes, sino una auto-eco-organización emergente con características propias dependientes y al mismo tiempo diferentes del entorno en el que se dan.

En el tercer piso, estaría lo que Morin llama el pensamiento complejo, es decir, la capacidad de pensar al ser humano que somos, desde las posibilidades que se han abierto en el diálogo las teorías anteriores y desde las reflexiones críticas del conocimiento que se han dado después de Husserl y Heidegger en la filosofía (Morin, 1997; Morin, 1996b, 202-217).

En una reflexión posterior, Morin nos dice que su gran empresa requiere sustituir el paradigma de simplificación de la ciencia clásica por un paradigma de complejidad que aún no puede nacer, porque el paradigma de simplificación aún no puede morir. Y en cuanto a su construcción epistemológica nos dice lo siguiente:
"Mi método integró en su seno cuarto aportaciones: -la aportación de una tradición filosófica de afrontar contradicciones que, nacida en Occidente con Heráclito, prosiguió con Nicolás de Cusa, Pascal, Hegel, Marx, Adorno, Jung, y se vio científicamente prolongada con Böhr, Gödel, Lupasco; -la aportación de las "tres teorías" (información, cibernética, sistema) y de las teorías de la auto-organización y de la autoproducción (Von Forester, Maturana, Atlan); -la reflexión filosófica sobre la naturaleza de la ciencia (Husserl, Heidegger); y -la reflexión epistemológica sobre la primera revolución científica del siglo XX, suscitada por la irrupción de lo incierto (desorden, indeterminación, azar, caos) y efectuada por Bachelard, Popper, Lakatos, Kuhn, Feyerabend; añadí a ello una reflexión sobre la segunda revolución científica en curso que, al objeto de las ciencias compartimentadas, sustituye el carácter inseparable de las realidades sistémicas (ecología científica, ciencias de la tierra, cosmología)... -y de una manera metacognitiva Morin continúa su reflexión diciendo: Yo no sólo he cientifizado una gran corriente filosófica, sino que he querido que pueda ponerse de relieve un pensamiento pertinente a partir de un continuo ir y venir entre filosofía y ciencia. He intentado prolongar científicamente la filosofía y filosóficamente la ciencia. -y como era de esperarse ante una irrupción de un tipo de pensamiento que no respeta las clausuras disciplinares, las críticas y descalificaciones no faltaron. Por ello, de manera muy sarcástica concluye nuestro autor diciendo:- iSacrilegio! iCuántas fronteras cruzadas sin pasaporte! iCuántos santuarios profanados! iCuántos odios ineptos por una aventura de buena voluntad! iQué imposibilidad de comprender que la pertinencia se adquiere al superar la especialización y no encerrándose en ella! Mi esfuerzo se dirige a vincular lo empírico y lo teórico, lo concreto y lo abstracto, la parte y el todo, el fenómeno y el contexto. Sí, me consagre a las ideas, pero no a las generales, sino a 
las genéricas: las ideas nucleares, las que están en el núcleo de pensamiento o creencia, las que son capaces de desorganizar y organizar estos sistemas, las que permiten generar un pensamiento. Son lo que yo denomino, desde otro ángulo, los paradigmas" (Morin, 1996b, 274-276).

Todo este andamiaje se encuentra estructurado en su voluminosa obra en seis tomos que se llama el Método (Morin, 1983, 1986, 1988, 1992, 2003a, 2006) Desafortunadamente en el lector desapercibido, cuando lee esta obra y debido a su densidad, no queda suficientemente claro que lo que está haciendo Morin es una construcción epistemológico de una nueva racionalidad, lo que él llama paradigma de complejidad o de manera más sencilla Pensamiento Complejo en tanto estrategia para lograr una humanidad otra. Esta apuesta es la que aparece de manera más trasparente en sus escritos, por decirlo así pedagógicos (Morin, 1993, 1984, 2001a, 2001b, 1998, 2003b) a partir de los cuales el autor comienza a ser reconocido por sus lectores como un pensador planetario, como un intelectual que le apuesta a la emergencia de una humanidad que como "comunidad de destino" se enfrenta a la supervivencia de la especie humana, y esta vez, en sentido planetario. De esta manera lo que está en juego no es un simple articulado teórico-conceptual de tipo complejo, sino la humanidad actual en medio de un proceso histórico de planetarización (Morin, Roger, \& Motta, 2003b).

En Morin, hay una crítica muy fuerte a la sociedad contemporánea, pues para él la sociedad actual es una sociedad que a pesar de sus grandes progresos, de sus grandes conocimientos, de su innegable desarrollo tecno-científico, sigue siendo una sociedad bárbara que se encuentra en su edad de hierro planetaria ${ }^{1}$ como en la prehistoria de la evolución de su espíritu -mind- (Morin, 1992, 216-244). La sociedad, para Morin ha perdido su horizonte como humanidad y por tanto hay que hacer una apuesta antropolítica que posibilite la construcción de una sociedad más civilizada y que posibilite a un mismo tiempo la apropiación del planeta como una "tierrapatria" (Morin \& Kern, 1993).

En síntesis, la complejidad en Morin no trata de los asuntos propios de las así llamadas "ciencias de la complejidad", sino de un nuevo horizonte epistemológico para organizar el pensamiento de tal manera que posibilite la emergencia de una nueva manera histórica de ser, que posibilite la transformación de la hominización en humanidad (Morin, 2001, 120122).

Morin, le apuesta entonces a un paradigma de complejidad y a un pensamiento complejo, que busca -y esta es su novedad- la creación de unos principios de inteligibilidad que nos permitan comprendernos de una manera distinta. La complejidad y más precisamente el pensamiento complejo en su vertiente moriniana, integra lo humano como elemento constitutivo y constituyente de la complejidad. Por ello, la complejidad en Morin no es un discurso terminado, acabado, cerrado, sino una orientación hacia aquello que tenemos que volver la mirada si queremos asegurar la supervivencia de la humanidad en la era planetaria. Hay por tanto una gran diferencia entre, por un lado, una preocupación por comprender las cuestiones funcionales relativas al conocimiento en las situaciones límites en las ciencias del siglo XX: las así llamadas "ciencias de la complejidad", y por otro, el desafío por comprender el "Conocimiento del conocimiento" (Morin, 1988). Complejizar la complejidad funcional para reubicarla en el ámbito de la comprensión humana es la tarea que se propone Morin desde la apuesta por un pensamiento complejo en tanto condición de posibilidad para una teoría de la organización y de un paradigma de complejidad, los cuales a su vez son la condición de posibilidad para un pensamiento complejo (Morin, 1983; 1986). Se trata únicamente de un pensamiento para comprender la complejidad de lo real, que por lo demás siempre nos desbordará, sino que además implica, la complejización del pensamiento de la complejidad para dilucidar nuestra condición huma-

1 Metáfora que Morin recoge de Max Weber para quien la sociedad moderna además de haberse desencantado se ha convertido en una "jaula de hierro". 
na (humana conditio) en la era que se ha convertido en planetaria. Dicho de otra manera, el hombre hace parte de esa complejidad que a su vez lo constituye. Pero, el hombre es el único que pregunta por esa realidad porque tiene consciencia del distanciamiento con ella.

En síntesis, Morin quiere responder a la pregunta conductora que no se hacen las "ciencias de la complejidad, a saber: ¿Dónde está el que pregunta en medio de las "ciencias de la complejidad"? La complejidad, en sentido del autor, implica el paso de la pregunta conductora a una pregunta fundamental: ¿Quién es éste ser, que en su modo histórico de ser, es capaz de construir tan impresionantes conocimientos sobre lo que él mismo es, sin tener que quedar reducido a lo que esos conocimientos nos dicen?

Dicho de otra manera, el hombre para Morin, no puede ser comprendido a la manera como se comprenden los fenómenos en las "ciencias de la complejidad". Por tanto, el pensamiento complejo intenta complejizar el pensar sobre la complejidad para que ésta pueda dirigirse hacia aquello que no cabe en las estructuras del conocimiento funcional; para que quien piensa pueda convertirse en el centro de atención del mismo pensamiento. Lo cual exige, como lo indica Morin una reforma del pensamiento: un cambio de racionalidad (Morin, 2003, 91-102). La reforma del pensamiento en Morin, aspira a la superación de un pensamiento simplificador, de un principio del pensamiento que opera a partir de una lógica disyuntora-reductora, de una explicación racional del mundo que se instauró con el pensamiento científico-clásico y en la sociedad occidental en los últimos cuatro siglos e invita a una transformación paradigmática del conocimiento que articulando las intuiciones de las corrientes, enfoques y escuelas más significativas del pensamiento actual, busca una comprensión compleja de lo real como una comprensión hipercomplejidad de la condición humana (humana conditio) en la era planetaria.

El pensamiento complejo busca desarrollar estrategias de pensamiento y acción para enfrentar el mundo (Osorio, 2008b); busca la consolidación de un paradigma de complejidad que como tal no existe, sino que está haciéndose y donde se nos propone reconocer lo paradigmático del conocimiento, sobre todo a partir de las manifestaciones del paradigma de simplificación (Osorio, 2003). Como todo modo de pensar, el pensamiento complejo debe complementar y confrontar el modo de pensar que separa con un modo de pensar apoyado en unos principios de conocimiento capaces de concebir la religación, la contextual, lo global (Morin, 1994, 87-110). El pensamiento complejo, al mismo tiempo que lucha por conectar lo separado, debe ser capaz de reconocer lo a-normal, lo singular, lo concreto. En esta apuesta por comprender la complejidad organizada el pensamiento complejo tiene que establecer distinciones, trabajar con categorías, diseñar lógicas, construir gramáticas (Solana, 2001). A estas estrategias del pensamiento humano, Morin (1996a, 2-10) les llama "operadores del pensamiento que relaciona", ellas son:

\subsection{El principio del bucle recursivo}

La cibernética introduce en el pensamiento el concepto de retroacción para superar la causalidad lineal y hacernos concebir la paradoja de un sistema en el cual el efecto retroactúa en la causa y la modifica. Con ello introduce el principio de retroacción o de causalidad en bucle. Ejemplo de esto es el sistema de calefacción regulado por un termostato. Morin recoge este concepto, pero lo lanza más allá de la idea cibernética de regulación al introducirlo dentro de la idea de organización (Solana, 2001). De esta manera la noción de regulación queda superada por idea de organización y más exactamente por la de autoproducción y auto-organización.

"El bucle recursivo supera la noción de regulación y la de autoproducción y autoorganización. Se trata de un bucle generador en el que los productos y los efectos son en sí mismos productores y causantes de lo que se produce. Así, los individuos somos los productos de un sistema de reproducción que surge de los tiempos más remotos, pero ese sistema no puede reproducirse salvo que nosotros mismos nos convirtamos en los productores al acoplarnos. Los individuos humanos producen la sociedad en $y$ por sus interacciones, pero la sociedad, en tanto todo emergente, produce la huma- 
nidad de estos individuos al aportarles el lenguaje y la cultura" (Morin, 2001, 100).

El principio de recursividad es, pues, un principio del pensamiento fundamental para lograr asir no sólo la retroacción de los productos sobre el productor, sino reconocer y traducir, en términos de teoría, aquellas entidades y características que son productos a la vez que productores y causas del mismo proceso que las produce. Y dado que esta praxis organizacional se da en toda organización viviente, la idea de la auto-re-organización es una de las herramientas vitales del pensamiento complejo dado que este está constreñido a percibir, concebir y pensar de manera conjunta todo aquello que nos abarca, y que llamamos realidad.

\subsection{El principio de auto-eco-explicación}

"Este principio es válido para todo ser vivo que, para guardar su forma (perseverar en su ser) debe autoproducirse y auto-organizarse gastando y sacando energía, información y organización del ecosistema en donde existe. Dicho ser vivo debe concebirse como un ser auto-eco-organizador, ya que la autonomía es inseparable de la dependencia" (Morin, 1996a, 2). El principio de auto-eco-explicación se opone a la lógica disyuntiva y reductiva del pensamiento simplificador. Es decir, a las dos siguientes explicaciones de los fenómenos humanos: Por un lado, al aislamiento del fenómeno de su "medio" y por otro a la explicación externa u objetivante de la realidad.

En síntesis a hacer del "fenómeno" un mero producto de determinaciones externas y considerarlo en su entorno, teniendo siempre en cuenta que la consideración de algo como entorno o ecosistema depende del punto de vista o focalización adoptada por el observador/conceptuador.

En virtud del principio de auto-eco-explicación no puede haber descripción, ni explicación de los fenómenos fuera de la doble inscripción y de la doble implicación en el seno de una dialógica compleja que asocie de manera complementaria, concurrente y antagonista las lógicas autónomas e internas propias del fenómeno por una parte y las ecológicas de sus entornos por la otra (Morin, 1983, 111).
El principio de auto-eco-explicación nos muestra por un lado, que la explicación de los fenómenos, debe considerar tanto la lógica interna del sistema como la lógica externa de la situación o entorno; debe establecer una dialógica entre los procesos interiores (niveles de percepción) y los exteriores (niveles de realidad) en su ir y venir constante (tercero incluido). Por el otro, que todo fenómeno autónomo (auto-organizador, auto-productor, auto-determinado) debe ser considerado en relación con "su" entorno o ecosistema.

En síntesis, el principio de auto-eco-explicación, nos indica que el pensamiento complejo debe ser un pensamiento ecologizado que, en vez de aislar el objeto estudiado, lo considere en y por su relación eco-organizadora con su entorno (Morin, 1991). Ahora bien, la visión ecológica no debe significar una reducción del objeto a la red de relaciones que lo constituyen. El mundo no sólo está constituido por relaciones, sino que en él emergen realidades dotadas de una determinada autonomía. De aquí lo que inseparablemente deba considerar el pensamiento complejo ecologizado sea la relación autoeco-organizadora del objeto con respecto a su ecosistema.

\subsection{El principio de emergencia}

Según el principio de emergencia, en las realidades (conjuntos o todos) organizadas emergen cualidades y propiedades nuevas a las que podemos llamar "emergencias" que no son reducibles a los elementos que las componen (partes), y que tampoco son la suma de las partes (todo), y que retroactúan sobre esas realidades.

"Se puede llamar emergencias a las cualidades o propiedades de un sistema que presentan un carácter de novedad con relación a las cualidades o propiedades de los componentes considerados aisladamente o dispuestos de forma diferente en otro tipo de sistema. A nivel del todo surgen propiedades nuevas que no estaban en las partes consideradas aisladamente o de manera sumativa" (Morin, 1986). 
El principio de emergencia nos muestra que no se puede sacrificar el todo a la parte -como hace el reduccionismo clásico, -pero tampoco sacrificar la parte al todo como hace el holismo contemporáneo-. No se puede de reducir el todo a la parte, ni la parte al todo, sino de establecer un vaivén continuo $e$ incesante entre el todo y sus partes.

\subsection{El principio hologramático}

El pensamiento complejo hace necesariamente uso de la abstracción, pero busca que sus producciones de conocimiento se construyan por referencia obligada a un contexto (cerebral, social, cultural, temporal). El pensamiento complejo busca integrar y globalizar, religando las partes al todo, el todo a las partes y las partes entre sí, pero tiene la conciencia de que es imposible conocer el todo.

Como lo dice la voz griega, holon significa todo. Pero no se trata de una totalidad. Es un todo que no totaliza. El principio hologramático nos guía y nos permite concebir una de las características más sorprendentes e importantes de la complejidad organizada: en una organización el todo está inscrito en cada una de sus partes, pero la totalidad no es la suma de las partes. Se trata, obviamente, de una inscripción estructural del todo en la parte.

La relación todo-partes/partes-partes/partes-todo, se presenta bajo tres modalidades holonómica, hologramática y holoscópica (ver tabla 1).

La noción de holograma parece capturar, siquiera sea de forma metafórica, un principio de organización general que estaría presente en muy diversos dominios de lo real: cada parte contiene dentro de sí el todo; cada parte debe su singularidad justamente porque controlada por la organización del todo (producido por las interacciones de las partes), una pequeña parte del todo se expresa en él, pero al mismo tiempo sigue siendo portadora de las virtualidades del todo. Parece claro, entonces, que el pensamiento complejo dispone de la posibilidad de religar el todo con las partes y las partes con el todo, así como la posibilidad de no recaer en las trampas de la simplificación.
Tabla 1. Modalidades de prestación de la relación todopartes/partes-partes/partes-todo 2

\begin{tabular}{|l|l|l|}
\hline Modalidad & \multicolumn{1}{|c|}{ Definición } & \multicolumn{1}{c|}{ Ejemplo } \\
\hline Holonómica & $\begin{array}{l}\text { El todo en tanto que } \\
\text { todo puede gobernar } \\
\text { las actividades locales. }\end{array}$ & $\begin{array}{l}\text { El cerebro en tanto que } \\
\text { todo gobierna los nú- } \\
\text { cleos de neuronas que } \\
\text { lo gobiernan. }\end{array}$ \\
\hline Hologramática & $\begin{array}{l}\text { El todo puede, aproxi- } \\
\text { madamente, estar ins- } \\
\text { crito o engramado en } \\
\text { la parte inscrita en el } \\
\text { todo. }\end{array}$ & $\begin{array}{l}\text { En cada célula está la } \\
\text { totalidad de la infor- } \\
\text { mación genética del } \\
\text { organismo. }\end{array}$ \\
\hline Holoscópica & $\begin{array}{l}\text { El todo puede estar } \\
\text { contenido en una re- } \\
\text { presentación parcial de } \\
\text { un fenómeno o de una } \\
\text { situación. }\end{array}$ & $\begin{array}{l}\text { En los procesos de re- } \\
\text { memoración } \\
\text { y de percepción. }\end{array}$ \\
\hline
\end{tabular}

En este contexto Morin recupera el imperativo cognitivo propuesto por Pascal según el cual es imposible conocer el todo sin conocer las partes y conocer las partes sin conocer el todo:

"Siendo todas las cosas causadas y causantes, ayudadas y ayudantes, mediatas e inmediatas, y manteniéndose todas por un lazo natural $e$ insensible que liga a las más alejadas y a las más diferentes, yo tengo por imposible conocer las partes sin conocer el todo, así como el conocer el todo sin conocer particularmente las partes" (Pascal, 1973, 62).

\subsection{El principio dialógico o dialogización}

El principio de dialogización es un principio del pensamiento que une o pone en relación ideas o principios de dos lógicas que de suyo son antagónicas. Esto es, él une dos principios o ideas que se excluyen mutuamente, pero que son inseparables y complementarias dentro de una misma realidad o fenómeno.

"Niels Böhr, por ejemplo, reconoció la necesidad de concebir las partículas físicas al mismo tiempo como corpúsculos y como ondas. Los individuos humanos son como corpúsculos autónomos desde un determinado punto de vista $y$, al mismo tiempo, se

\footnotetext{
2 Fuente: Elaboración propia.
} 
desvanecen desde otro punto de vista, en el interior de las continuidades que son la especie y la sociedad: cuando se consideran la especie o la sociedad, el individuo desaparece; cuando se considera el individuo, la especie y la sociedad desaparece. El pensamiento debe asumir dialógicamente los dos términos que tienden a excluirse" (Morin, 2001, 101).

El principio dialógico faculta al pensamiento en sus asociaciones y conexiones de conceptos o enunciados que se contradicen el uno al otro, pero que deben aparecer como dimensiones articuladas de lo mismo. Su vocación epistemológica es captar el modo de existencia, funcionamiento e independencias contextuales de un "fenómeno" complejo.

El principio dialógico afina al pensamiento para captar las contradicciones fecundadas que aparecen toda vez que tiene que vérselas con un sistema complejo, con la dimensión generativa de su organización. Así, para poder describir la dinámica de un sistema complejo es vital concebir una dialógica: un diálogo de lógicas entre orden/desorden/organización y entre aquello que es de suyo concurrente, antagónico y complementario.

El principio dialógico conduce a la idea de "unidualidad compleja" o unitas multiplex. La unidualidad entre dos términos significa que éstos son, a la vez, ineliminables e irreductibles. Ninguno de los dos términos es reducible al otro (y en este sentido hay dualidad), pero tampoco son nítidamente separables, pues confluyen mutuamente (y en este sentido son uno). Por separado cada término o cada lógica resultan insuficientes, por lo que hay que relacionarlos y hacerlo en forma de bucle.

El "paradigma de simplificación" nos enseño a conocer dividiendo, separando, antagonizando. El pensamiento complejo nos invita y reta para pensar religando, juntando, contextualizando; nos insta a ver $e$ integrar los antagonismos y a desarrollar una visión poliocular de la realidad.

"La unidad de un ser, de un sistema complejo, de una organización activa no es entendida por la lógica identitaria, ya que no sólo hay diversidad en lo uno, sino también relatividad de lo uno, alteridad de lo uno, incertidumbres, ambigüedades, dualidades, escisiones, antagonismos. Hay que entender que lo uno es en realidad relativo con respecto a lo otro. No se le puede definir únicamente de manera intrínseca; necesita, para poder surgir, de su entorno y de su observador. Lo uno es pues complejo. Es una identidad compleja. Es, como todo lo que produce individualidad, autonomía, identidad, permanencia en sus Unitas múltiplex" (Morin, 1986).

\subsection{El principio de reintroducción del cognoscente en todo conocimiento}

Para Morin es necesario re-introducir al sujeto en todos los procesos del conocimiento y sacar a la luz la problemática cognitiva que oculta el pensamiento y el paradigma simplificador, a saber: que el conocimiento no es un espejo de las cosas o del mundo exterior, sino una reconstrucción-traducción por un espíritu-cerebro, en una cultura y en un tiempo determinado.

"Todas las percepciones son a la vez traducciones y reconstrucciones cerebrales, a partir de estímulos o signos captados por los sentidos; de ahí que es bien sabido, los innumerables errores de percepción que sin embargo nos llegan de nuestro sentido más fiable, el de la visión. Al error de percepción se agrega el error intelectual. El conocimiento en forma de palabra, de idea, de teoría, es el fruto de una traducción-reconstrucción mediada por el lenguaje y el pensamiento y por ende conoce el riesgo del error... De ahí provienen los innumerables errores de concepción y de ideas que sobrevienen a pesar de nuestros controles racionales" (Morin, 2001b, 22).

De lo anterior debemos colegir que la reforma del pensameinto es de naturaleza paradigmática y no 
programática. En ella se pone en juego el principio a parir del cual se organiza el conocimiento. Por tanto, la lucidez a la que tiende el pensamiento complejo y la reforma paradigmática del conocimiento depen$\mathrm{de}$, para Morin, de la manera de organizar nuestras ideas, de los paradigmas (Osorio, 2008b, 98-121; 2010, 142-166).

\begin{abstract}
"Por ello, tenemos que comprender que la revolución se juega hoy no tanto en el terreno de las ideas buenas o verdaderas opuestas en una lucha de vida o muerte con las ideas malas y falsas, sino en el terreno de la complejidad del modo de organizar las ideas. La salida de la 'edad de hierro planetaria' y de la 'prehistoria del espíritu' nos exige pensar de forma radicalmente compleja" (Morin, 1992, 244).
\end{abstract}

\subsection{El principio de borrosidad}

Finalmente y aunque Morin no lo postule de manera explícita, el principio de borrosidad es un principio activo de todo su pensamiento. El principio de borrosidad se opone a la idea de que todos los enunciados y conceptos propios de las organizaciones complejas, se puedan poner en negro sobre blanco, sin ambigüedad. El principio de borrosidad le permite al pensamiento razonar con enunciados y conceptos inciertos o indecidibles (Morin, 2001, 83-96).

El principio de borrosidad es un principio que se opone al principio de bivalencia y a la tendencia a no reconocer entidades de medianía. Es, pues un principio que nos ayuda a concebir entidades mixtas o mezclas producidas en el seno de una organización compleja. Así, el principio de borrosidad, nos posibilita sobrepasar algunas de las dicotomías clásicas: espíritu/materia, hombre/mujer, ser/no-ser. En suma, ir más allá de las ideas claras y distintas al estilo cartesiano.

Desde este contexto podemos comprender por qué el pensameinto complejo busca la otra orilla del pensamiento cartesiano, pues:

"A diferencia de un Descartes, que partía de un principio simple de verdad, es decir, que identificaba la verdad de las ideas claras y distintas, y por ello, podía proponer un discurso del método de algunas páginas, yo hago un discurso muy largo en busca de un método que no se revela por ninguna evidencia primera, y que debe elaborarse en el esfuerzo, el riesgo y la incertidumbre" (Morin, 1984b, 316).

Con lo anterior expuesto podemos observar que Morin avanzando hacia una forma de conocimiento que sin dividir y simplificar la realidad, comprende religando, distinguiendo, complejizando. Morin busca un "método" para el pensamiento que supere las dicotomías del conocimiento disciplinar y que posibilite un aprendizaje relacional: un pensamiento complejo.

Teniendo en cuenta lo anterior, podemos decir que la preocupación fundamental de Morin no es la inteligibilidad científica y compleja de muchos de los factores que constituyen el mundo físico, biológico, químico... sino la preocupación por pensar la hipercomplejidad humana que somos y nos constituye desde sus fuentes físico-químicas, biológicas y antropo-sociales. Aunque para ello tenga que hacer una verdadera reforma del pensamiento y de la educación, pues desde la concepción actual es imposible hacerlo.

Lo que ha impedido la emergencia de una sociedad otra, ha sido en gran parte la incomprensión de esa complejidad que somos y esa incomprensión se debe, según Morin, al paradigma simplificador, disyuntor y reductor con el que opera la ciencia moderna.

\section{El ideal de racionalidad de la ciencia clásica}

La organización social, la producción y aplicación del conocimiento y la gobernabilidad del mundo mediante la centralización del poder político dieron las características específicas, desde el siglo XVI a la naciente sociedad moderna europea. Este proceso socio-histórico, cultural, epistemológico y espiritual se fraguo en medio de las relaciones complejas entre la organización del sistema social a través de la consolidación y expansión de una economía de mercado 
capitalista; la organización de la comunidad política a través de la constitución de los estados nacionales y de regímenes políticos democráticos y representativos, y la producción de un tipo de conocimiento que se consolido en el siglo XIX mediante la institucionalización de la construcción de los saberes especializados, que a su vez consolido lo que Snow (1980) ha llamado la separación entre la cultura científica y la cultura humanística.

De esta manera, la sociedad moderna europea consolidará una nueva e incierta forma de vida que entronizará, vía racionalidad científica, una escisión entre la vida humana y la vida del planeta y del universo. Dicha situación ha traído para todas las dimensiones y esferas de la vida humana y en todos los niveles en los que se construye la identidad humana una fragmentación social, cultural, personal y epistémica que presenta hoy indicadores críticos.

El hombre de la modernidad convertido en sujeto de conocimiento pretendió ser capaz de observar al mundo objetivamente, es decir, con independencia de la mirada sobre él mismo y aunque de hecho esto era imposible, confió ciegamente en su posibilidad. Pensar el mundo independientemente del pensamiento que lo está pensando es pues, la gran paradoja de la epistemología clásica (Fox Keller, 1995).

A esta perspectiva del conocimiento en la que el sujeto no se mete en lo conocido a la manera en que un espejo no se mete en la imagen por el reflejada, o en la que un pintor no se mete en su cuadro, es justamente lo que desarrollo un conocimiento representacionista de la realidad, que es una de las características fundamentales de la epistemología y de la ciencia clásica.

La ciencia clásica cree en la posibilidad de re-presentar en la mente de quien conoce una imagen que es copia fiel de la realidad y aunque esto en la práctica era imposible, la reflexión filosófica moderna lo impuso como presupuesto fundamental del conocimiento de la realidad. Para la muestra este texto de John Locke:

"Supongamos que la mente es, como nosotros decimos, un papel en blanco, vacío de caracteres, sin ideas ¿Cómo se llena? A esto respondo con una palabra: con la experiencia. En ella se funda todo nuestro conocimiento, y de ella se deriva todo en último término. Nuestra observación, ocupándose ya sobre objetos sensibles externos o ya sobre las operaciones internas de nuestras mentes, percibidas y reflejadas por nosotros mismos, es la que abastece a nuestro entendimiento con todos los materiales del pensar. Cuando las ideas simples se ofrecen a la mente, el entendimiento no puede rehusar tenerlas, ni alterarlas cuando están impresas, ni borrarlas para hacer otras nuevas, de la misma manera que un espejo no puede rehusar, alterar o destruir las imágenes o ideas que los objetos puestos delante de él producen" (Locke, 1982, 110).

La imagen representacionista del conocimiento que supone por un lado que el conocimiento es reflejo fiel del mundo observado -sin el observador-, y que el sujeto es totalmente pasivo, -como el espejo-, para percibir y concebir la realidad exterior, no es capaz de abordar la experiencia humana en su totalidad, si no sólo aquella que se identifica con la experimentación del universo comprendido como una máquina perfectísima. El ideal de la ciencia clásica centrando la atención en las teorías como sistemas legaliformes expresados en el lenguaje de las matemáticas y verificados única y exclusivamente desde el imperio de la lógica y de la contrastación experimental dejaron en el olvido o peor aún, invisivilizaron la actividad creativa e inventiva de toda producción de conocimientos (Heidegger, 1994).

En síntesis tenemos entonces cuatro características básicas que permiten la consolidación del ideal de la racionalidad de la ciencia clásica:

- El primado de la razón, ésta entendida como fundamento absoluto para producir un conocimiento científico nuevo por su formulación, su lenguaje y su justificación.

- La idea de la inmutabilidad y pasividad de la naturaleza. La naturaleza, es objeto de indagación, una máquina perfectísima que se puede conocer 
a través de leyes invariables. El universo es semejante a sí mismo en todas sus manifestaciones, y por ello puede ser explicado a partir de leyes simples, que durante un tiempo bastante prolongado se identificaron con las formuladas por la física mecánica. La racionalidad altamente matematizada de la física legitimó al saber científico como único saber válido en detrimento y exclusión de otros saberes que se daban en la vida cotidiana y separó de manera tajante y violenta lo moral y valorativo como concerniente al ámbito de la subjetividad, de lo objetivo y verdadero concerniente al ámbito de la ciencia.

- El paradigma científico-filosófico de la modernidad logró separar de una manera abusiva, violenta y dramática el pensar como proceso y actividad vital de aquello que era pensado y de ese modo logró también desacoplar lo que en la vida es inseparable: la vida como conocimiento y el conocimiento como actividad fundamental de vida (Maturana \& Varela, 1990). Dicho de otra manera, estableció la separación sujeto/objeto como meollo para la cognición e implantó la evidencia lógica como criterio para el conocimiento del mundo.

- Cultivó la creencia de que el saber científico era capaz de proveer al hombre de poder para dominar la naturaleza. Según Bacón, saber es poder y el hombre tiene que torturar a la naturaleza para que ella le de sus secretos. Como nos recuerda Nicolescu $(2006,4)$.

"La ciencia moderna nació mediante un violento rompimiento con la antigua visión del mundo. Se fundamentó en la idea -sorprendente y revolucionaria para la era- de una separación total entre el sujeto cognoscente y la realidad, que era asumida como completamente independiente al sujeto que la observaba. Este rompimiento permitió a la ciencia desarrollarse independientemente de la teología, la filosofía y la cultura. Era un acto de libertad positivo. Pero en nuestros días, las consecuencias extremas de ese rompimiento, encarnados por la ideología del cientismo, (es decir de la lógica implacable de la eficacia por la eficacia), se han convertido en un riesgo potencial de destrucción de nuestras propias especies. Las consecuencias de éste cientificismo han sido considerables: el único conocimiento digno de ese nombre debe ser, por tanto, el científico, objetivo; la única realidad digna de este nombre debe ser, por supuesto, la realidad objetiva, gobernada por leyes objetivas. Todo conocimiento que no sea el conocimiento científico es, pues, enviado al infierno de la subjetividad, tolerado cuando mucho, como un embellecimiento sin significado o rechazado con desdén como fantasía, una ilusión, una regresión o un producto de la imaginación. La objetividad, puesta como el criterio supremo de verdad, tiene una consecuencia inevitable: la transformación del sujeto en un objeto. La muerte del sujeto es el precio que pagamos por el conocimiento objetivo. El ser humano se volvió un objeto -un objeto de explotación del hombre por el hombre, un objeto de experimentos de ideologías que se proclaman científicas, un objeto de estudios científicos para ser disectado, formalizado y manipulado-. El hombreDios se ha convertido en hombre-objeto, del cual el único resultado puede ser la auto-destrucción".

\section{Emergencia de una nueva racionalidad}

Además de las consecuencias anteriores, la influencia ideológica de la racionalidad científica clásica condujo también a la desactivación cognoscitiva del hombre común y la vida cotidiana, relegándolos a la condición de receptores pasivos de los avances científico-técnicos. Sin embargo, en la segunda mitad del siglo XX los nuevos problemas que aparecieron ante el hombre común, en especial el deterioro del medio ambiente, las consecuencias negativas de la introducción de algunos resultados científicos, el uso de los conocimientos con fines militares o su apropiación como bienes privados, han venido produciendo la emergencia de una nueva consciencia en el hombre del común, que ha cobrado formas sociales 
colectivas en movimientos y grupos de presión, los que han tenido una influencia notable en algunos avances cognoscitivos tendientes a la superación de la racionalidad clásica en tanto que ponen a la sociedad en el riesgo de desaparecer (Sotolongo \& Delgado, 2006; Beck, 2006).

Estas reacciones ciudadanas plantean serios desafíos para la producción de los sistemas científicos, para la legitimidad de las instituciones sociales y para la organización de los sistemas educativos en todos sus niveles. Al mismo tiempo, implican nuevas perspectivas que replantean la relación hombre-hombre y hombre-naturaleza. Es decir nuevas perspectivas para la racionalidad humana (Potter, 1988, 1971; Illich, 2006, 2008; Osorio, 2008a).

Esto significa que la organización actual del sistema tecno-científico conlleva el surgimiento de problemas fundamentales que afectan la vida y la muerte de millones de hombres y mujeres. Por tanto, en este contexto, se vuelve vital pensar críticamente las implicaciones sociales, políticas, históricas y humanas de la actividad científica. Puesto que la ciencia no es una práctica neutral en relación a la vida y a la política, la significación epistemológica y social del conocimiento científico adquiere una nueva dimensión para la humanidad.

Desde la segunda mitad del siglo XX, hemos comenzado a comprender el mundo en términos de sistemas dinámicos, donde las interacciones entre los constituyentes de los sistemas y su entorno resultan tan importantes como el análisis de los componentes mismos. El mundo ha comenzado a dejar de ser un conjunto de objetos para convertirse en un enjambre de conexiones, de interacciones, de redes, de emergencias, de devenires, de incertidumbres, de contradicciones.

"En los seres vivos, y sobre todo en los seres humanos, se dan estructuras de un altísimo nivel de complejidad, las cuales están constituidas por sistemas de sistemas cuya comprensión desafía la agudeza de las mentes más privilegiadas. La naturaleza es un todo polisistémico que se rebela cuando es reducido a sus elementos. Y se rebela, precisamente, porque, así, reducido, pierde las cualidades emergentes del 'todo' y la acción de éstas sobre cada una de las partes. Este 'todo polisistémico', que constituye la naturaleza global, nos obliga, incluso, a dar un paso más en esta dirección. Nos obliga a adoptar una metodología transdisciplinaria para poder captar la riqueza de la interacción entre los diferentes subsistemas que estudian las disciplinas particulares. No se trata simplemente de sumar varias disciplinas, agrupando sus esfuerzos para la solución de un determinado problema, es decir, no se trata de usar una cierta multidisciplinariedad, como se hace frecuentemente; ni tampoco es suficiente, muchas veces, la interdisciplinariedad. Se requiere de una visión transdisciplinaria. Este proceso cognitivo exige respetar la interacción entre los objetos de estudio de las diferentes disciplinas y lograr la transformación e integración de sus aportes respectivos en un todo coherente y lógico. Esto implica, para cada disciplina, la revisión, reformulación y redefinición de sus propias estructuras lógicas individuales, que fueron establecidas aislada e independientemente del sistema global con el que interactúan, pues sus conclusiones lógicas, particulares, en forma aislada, ni siquiera serían 'verdad' en sentido pleno" (Martínez, 2003, 129-130).

Ante estos desafíos, a lo largo y ancho de la historia contemporánea han comenzado a emerger un nuevo campo de estudios e investigaciones vinculadas al problema de la racionalidad y como consecuencia de este proceso se ha ido constituyendo un campo heterogéneo y plural al que podemos referirnos con el nombre de transdisciplinariedad, está a su vez considerada como estrategia para enfrentar la complejidad actual en la que vivimos, nos movemos y existimos.

Este campo es una constelación en donde conviven de manera complementaria y contradictoria diversas teorías y propuestas metodológicas fundamentadas en diferentes marcos lógicos y epistemológicos y enraizadas en supuestos ontológicos y metodológicos 
diversos y muchas veces antagónicos. Pero, en todos estos intentos podemos encontrar como hilo conductor la búsqueda de una nueva racionalidad que supere el paradigma científico de la ciencia clásica y nos permita comprender el mundo y sus problemas y nos permitan una salida racional ante la crisis mundial. Nos encontramos, pues, ante la emergencia de una nueva racionalidad: la transdisciplinariedad.

\section{El surgimiento del conocimiento trans- disciplinar}

\begin{abstract}
"En la última década, ha aparecido un 'movimiento' intelectual y académico denominado 'transdisciplinariedad', el cual desea ir 'más allá' (trans), no sólo de la unidisciplinariedad, sino también, de la multidisciplinariedad y de la interdisciplinariedad. Aunque la idea central de este movimiento no es nueva, su intención es superar la parcelación y fragmentación del conocimiento que reflejan las disciplinarias particulares y su consiguiente hiperespecialización, y, debido a esto, su incapacidad para comprender las complejas realidades del mundo actual, las cuales se distinguen, precisamente, por la multiplicidad de los nexos, de las relaciones y de las interconexiones que las constituyen. Este movimiento que, por su gran apertura, es mucho más amplio y receptivo que una 'escuela' ideológica con reglas fijas de pensamiento, ha sido impulsado, sobre todo, por la UNESCO y por el CIRET (Centro Internacional de Investigaciones y Estudios Transdisciplinarios) de Francia" (Martínez, 2003).
\end{abstract}

El mundo planetario en el cual vivimos hoy, se caracteriza por ser un mundo en red, "en-redado" por múltiples interconexiones en la que los fenómenos, sean del tipo que sean: naturales y/o sociales depende unos de otros y se entienden desde su función y ubicación con el todo del cual hacen parte. No hay fenómenos aislados, no hay posibilidad de entendimiento fragmentado de la realidad. Para comprender este mundo complejizado se hace necesaria una nueva visión de la racionalidad humana, una nueva perspectiva para el conocimiento diferente a la que nos ofrecieron las concepciones de la racionalidad clásica. Necesitamos una nueva visión de la realidad, al mismo tiempo que una nueva organización de nuestro modo de pensar, de nuestro modo de percibir y de nuestro modo de valorar (Nicolescu, 1999).

Hoy partimos de un nuevo supuesto teórico: los problemas desafiantes que nos presenta el mundo actual no vienen organizados en bloques disciplinarios, y además desbordan cada vez más los métodos y las teorías que se han elaborado dentro de la organización disciplinaria del saber, que a su vez justificaban una perspectiva del conocimiento simplificador, disyuntor/reductor de la complejidad de lo real. Si la organización disciplinaria del saber nos obligaba a centrar el conocimiento del mundo desde "objetos" de conocimiento, la nueva organización nos obliga a pensar de otra manera dicha organización y a concebir la realidad de una manera totalmente distinta.

Este nuevo desafío a la racionalidad debería llevar, de manera necesaria, a una renovación sin precedentes de las instituciones universitarias que viven, hoy por hoy, de los conocimientos producidos en el siglo XIX, cuando los conocimiento se tenían que construir desde la organización disciplinar de los saberes, conocimientos necesarios para su momento, desde luego, pero anacrónicos para la situación actual.

A nivel universitario nos encontramos en medio de una gran paradoja consistente en que la universidad sigue enseñando la apropiación disciplinaria de los saberes desde la organización administrativa de facultades, programas y departamentos, sin ningún vínculo alguno entre ellos, mientras que la realidad que tenemos que pensar hoy se nos ha vuelto transdisciplinar, multireferencial e indisciplinada (Richard, 1998). Nuevamente de la mano de Martínez (2003, 120), podemos decir que:

"Las disciplinas académicas aisladas son menos que adecuadas para tratar los más importantes problemas intelectuales y sociales de nuestro tiempo. La separación de saberes se torna hoy, inoperante cuando se enfrenta a la realidad concreta que vivimos. Esencialmente, las disciplinas son conveniencias 
administrativas, que se acoplan bien con las necesidades de las instituciones académicas y que se perpetúan a sí mismas como organizaciones sociales. Pero cuando se enfrentan con los problemas básicos y reales de la vida, que exigen saber cómo producir suficiente alimento para la población, cómo asegurarle una buena salud, cómo garantizar su seguridad personal, cómo bajar el índice de inflación, cómo aumentar la tasa de empleo laboral o cómo ofrecer una explicación del sentido del universo, estas subdivisiones disciplinarias entorpecen y obnubilan la visión de la solución más de lo que la iluminan. Las disciplinas, que fueron originariamente instrumentos de maestría para manejar las realidades de la vida, se pueden convertir en medios de perpetuación de irracionalidades al aconsejar un mal uso del conocimiento en la sociedad moderna".

Sin embargo, con esta paradójica situación ha de quedar claro que la solución no será dejar de producir conocimiento, esto sería además de absurdo, irracional. Lo que hay que hacer es más conocimiento, pero no conocimiento disciplinar, sino transdisciplinar. No se trata tampoco de desechar los conocimientos disciplinares como si fueran algo repugnante, sino de buscar y encontrar una nueva forma de organizarlos: un paradigma de complejidad, una visión transdisciplinar para el conocimiento.

Hoy tenemos y podemos construir buscar conocimiento transdisciplinar que en diálogo con el pensameinto complejo nos permiten una nueva comprensión de la realidad que somos y nos constituye, y que nos posibilite una nueva manera de habitar la tierra en la era planetaria. Y para ello no podemos comenzar de cero. En la actualidad hay tres grandes enfoques que reclaman para sí esta novedad. Está el enfoque experimental que ve la transdisciplinariedad como una forma de investigación integradora desde problemas concretos y que se correspondería con lo que aquí vamos a llamar enfoques multi-poli o pluridisciplinares (Mittelstrass, 2003; Nowontny, 2006); el enfoque fenomenológico, que comprende la transdisciplinariedad como una herramienta para comprender los problemas reales involucrando para sus análisis transferencias metodológicas. Para nosotros esta forma transdisciplinariedad se corresponde con los enfoques interdisciplinarios que adquirieron fuerza y legitimidad en el Congreso de Zürich, Alemania en el año 2000 (Gibbons, 2006); y los enfoques complejos que piensan la transdisciplinariedad en relación a un nuevo tipo de organización del conocimiento de cara a los desafíos de la humanidad en la era planetaria (Osorio, 2010). Es decir, con un nuevo tipo de integración compleja del conocimiento, de los conocimientos y que trasciende la organización del saber en campos disciplinares. Esta perspectiva transdisciplinar tuvo sus comienzos con las reflexiones de Jean Piaget, Erich Jantsch y André Lichnerowicz, en el Congreso internacional denominado "Interdisciplinariedad: Problemas de la enseñanza e investigación en las universidades", financiado por la Organización Económica para la Cooperación y el Desarrollo (OCDE), en colaboración con el Ministro Francés de Educación y la Universidad de Niza, en el año de 1970 (Piaget, 1972).

Su enfoque fue retomado por el Centro Internacional para la Investigación y el Estudio Transdisciplinar (CIRET), de Francia, durante el Primer Congreso Mundial de Transdisciplinariedad, realizado en el Convento de Arrábida, Portugal, en Noviembre de 1994. En este Congreso, también se firmo "La Carta de Transdisciplinariedad" que recoge los planteamientos desarrollados por el físico rumano Basarab Nicolescu, por el pensador francés Edgar Morin y por el pintor brasilero Lima de Freitas en torno a la nueva comprensión ontológica, epistemológica, metodológica y espiritual del conocimiento científico y no-científico en la actualidad.

En lo que sigue desarrollaré la perspectiva de la transdisciplinariedad por cuanto que dicho enfoque es el único que ha profundizado en la transdisciplinariedad en tanto revolución ontológica, metodológica, epistemológica y espiritual del conocimiento humano en el contexto de una realidad compleja y planetaria. 
Para los pensadores que promueven este enfoque, la transdisciplinariedad no es únicamente una estrategia pragmática en torno a los problemas concretos de una investigación (multi-poli o pluridisciplinariedad), no es únicamente un enfoque ampliado desde el punto de vista metodológico para el análisis de fenómenos interrelacionados (interdisciplinariedad), sino que es, además de lo anterior, una nueva visión de la realidad, una nueva organización compleja (epistemológica) del conocimiento y una nueva actitud ante sí mismo, ante el conocimiento y ante el mundo. Para la presentación de este enfoque seguiremos las apuestas que viene haciendo el físico rumano Basarab Nicolescu.

\subsection{Disciplinariedad, multi-poli-pluridiscipli- nariedad, interdisciplinariedad y transdisci- plinariedad según Basarab Nicolescu}

Para Nicolescu (1996) la disciplinariedad es la organización del conocimiento científico a partir de campos o áreas especializadas del saber. Las disciplinas operan el conocimiento de las partes de un todo que por su inmensidad se hace imposible de comprender como todo. Descartes con sus reglas para guiar el espíritu hacia un saber verdadero e indubitable, ha sido el mejor exponente de este tipo de mentalidad.

Las universidades modernas, son la institucionalización necesaria para la transmisión y enseñanza de los conocimientos alcanzados de manera disciplinar o mejor aún, son las instituciones sociales que transmiten de manera pedagógica la adquisición de un saber organizado en disciplinas. Para ello, administrativamente crean las unidades académicas llamadas escuelas, facultades, departamentos o institutos de saberes fragmentados unos de otros, que se desarrollan aisladamente mediante los métodos más adecuados para el conocimiento de unos "objetos" funcionales del conocimiento. Y esto si tenemos en cuenta que el "todo" es concebido como un gran mecano, como un reloj perfectísimo en donde cada pieza funciona de manera repetitiva y sin fisuras, la comprensión no podría ser de otra manera. Las ciencias clásicas, desde esta perspectiva, son la "herramienta" más eficaz y más expedita para el conocimiento de un todo que funciona al estilo mecánico.
Pero, ¿Es esta nuestra manera de concebir la realidad? ¿Qué sucedería si el universo (la naturaleza en la ciencia clásica) ya no es considerado como un mecano, sino como un polisistema que se produce y auto-reproduce a partir de, desde y por medio de la interacción de sus subsistemas, que se conciben a su vez por las relaciones entre ellos y por las relaciones entre ellos con un todo emergente? Sencillamente que el conocimiento de la realidad como conocimiento de las partes y como suma de las mismas se torna profundamente inadecuado. Insistir en la comprensión de ese todo dividido en partes desde conocimientos disciplinares, hoy por hoy, además de inadecuado, ineficaz. ¿Cómo buscarle la cuadratura al círculo?

Para Nicolescu las miradas profundas de las disciplinas son importantes y necesarias, pero al mismo tiempo insuficientes de cara la comprensión de la realidad que ha dejado de ser mecánica y que ya no puede ser comprendida de manera disciplinar. La multi-poli o pluridisciplinariedad, la interdisciplinariedad y la transdisciplinariedad tienen en común, para este autor, la búsqueda de un conocimiento que está más allá de las disciplinas. La multi-poli o pluridisciplinariedad, así como la interdisciplinariedad se distinguen de la transdisciplinariedad no sólo por la manera de articular el conocimiento, sino también, por lo que se busca con el mismo: La multi, poli o pluridisciplinariedad, así como interdisciplinariedad buscan ir más allá del conocimiento disciplinar, pero no logran salirse del marco de conocimiento disciplinar. La transdisciplinariedad, que hunde sus raíces en la multi, poli o pluridisciplinariedad y en la interdisciplinariedad, pero va más allá de ellas posibilitando una nueva articulación de los saberes, una nueva concepción del conocimiento y una nueva comprensión de la realidad.

"La pluridisciplinariedad consiste en el estudio de un objeto de una sola y misma disciplina, por varias disciplinas a la vez. Por ejemplo, una pintura de Giotto puede ser estudiada por la historia del arte, por la física, la química, la historia de las religiones, la historia de Europa y la geometría. El objeto en última instancia, se verá enriquecido por la intersección de varias discipli- 
nas. El conocimiento del objeto disciplinar es profundizado desde un enfoque multidisciplinario fértil. La investigación pluridisciplinaria ofrece un plus a la disciplina en cuestión (la historia del arte, en nuestro ejemplo), pero ese "plus" se encuentra al servicio exclusivo de la misma disciplina. En otras palabras, el enfoque pluridisciplinario desborda los límites disciplinarios, pero su finalidad sigue estando en el marco de la investigación disciplinaria" (Nicolescu, 1996, 37; 2003, 180).

Cuando caracterizamos la perspectiva disciplinar desde el campo investigativo, encontramos que los investigadores pueden pertenecer a diversas disciplinas o a la misma pero superespecializada. Aquí cada uno trabaja de manera independiente ateniéndose a su propio método y no necesita conocer el trabajo de los demás. Simplemente todos colaboran con un proyecto común. En este proyecto común hay, -la mayoría de las veces-, un investigador principal que es quien ha planeado el proyecto, quien lo supervisa, quien lo anima y quien al final lo articula. La articulación del conocimiento que será pluridisciplinar se hará al final de la investigación, desde los resultados de cada uno de los investigadores ha realizado, no se detiene en la manera en que fueron construidos, puesto que lo importante son los resultados de la investigación y no su construcción colectiva. El producto o los productos de investigación integran los aportes particulares de cada investigador respetando su particularidad y de esta manera se pueden apreciar varias miradas disciplinares sobre un mismo objeto disciplinar de la investigación.

"La interdisciplinariedad tiene un objetivo diferente al de la pluridisciplinariedad. Se refiere a la transferencia de métodos de una disciplina a otra. Se pueden distinguir tres grados de interdisciplinariedad: i) Por el grado de aplicación. Por ejemplo, los métodos de la física nuclear transferidos a la medicina llevan a la aparición de nuevos tratamientos contra el cáncer, ii) por el nivel epistemológico. Por ejemplo, la transferencia de métodos de la lógica formal en el derecho genera análisis interesantes en la epistemología de la ley, iii) por el grado de generación de nuevas disciplinas. Por ejemplo, la transferencia de métodos de las matemáticas en la física ha llevado a la físico-matemática, de la física de partículas a la astrofísica, a la cosmología cuántica, de las matemáticas a los fenómenos metereológicos a la teoría el caos, de la informática a los fenómenos artísticos al arte digital. Como la pluridisciplinariedad, la interdisciplinariedad desborda las disciplinas, pero su propósito se incluye también en la disciplina de investigación." (Nicolescu, 1996, 38).

Un proyecto de investigación bajo el enfoque interdisciplinar consistirá en la integración de los resultados de investigación. Pero en este caso y a diferencia de la investigación poli o multidisciplinar, sobre todo en el caso de la generación de nuevas disciplinas, la integración se hace desde el comienzo a partir de un diálogo abierto entre los investigadores y de los aportes que cada investigador y su método pueden brindar para la construcción común del objeto de análisis. Adicional a esto, al finalizar la investigación, los resultados son validados por cada uno de los miembros del equipo, lo cual lleva en muchos casos a una superación de los esquemas cognitivos con los que opera una determinada disciplina. Por tanto, los resultados de investigación pueden expresarse a través de una novedosa y creativa interpretación de la realidad estudiada o mediante la construcción de un nuevo esquema cognitivo: la interdisciplinariedad.

Para Nicolescu (1996) pese al desplazamiento disciplinar que supone el enfoque interdisciplinar, los resultados del estudio no rebasan suficientemente el marco disciplinar, puesto que la preocupación del conocimiento sigue estando en el objeto de conocimiento y no en la transformación de la realidad estudiada. Adicionalmente a esto, la comprensión ontológica de la investigación interdisciplinaria no tiene en cuenta que no existe una realidad, sino varias comprensiones de la realidad, y que en cada caso se dan a su vez, diferentes niveles de comprensión, como lo veremos más adelante. Por tanto la investigación interdisciplinar tampoco logra superar el marco de análisis del paradigma disciplinar. 
Para autores como Morin y Nicolescu, únicamente el enfoque transdisciplinar del conocimiento trasciende el paradigma disciplinar al superar no sólo el "objeto" de conocimiento, sino además la ontología que ha hecho posible el surgimiento del saber en campos especializados, comprendiendo la realidad y el hombre que hace parte de la misma de una manera totalmente diferente.

"La transdisciplinariedad, consiste como el prefijo 'trans' indica, a lo que está a la vez entre, a través y más allá de toda disciplina.

Su objetivo o finalidad es la comprensión del mundo actual, donde uno de sus imperativos es la unidad del conocimiento" (Nicolescu, 1996, 38).

El término transdisciplinar no le vino a Nicolescu del cielo, ni ha sido sacado de la manga del mago, sino del intenso trabajo que él ha realizado en la física de partículas. Por ello, para él, es desde este campo de conocimiento de donde arranca el desafío transdisciplinar.

"El término transdisciplinar no me vino del cielo o sólo del placer de respetar la etimología de la palabra trans, sino de mis largos años de práctica en la física cuántica. Para un extraño, puede parecer paradójico que sea justamente desde el propio corazón de las ciencias exactas que arribemos a la idea de los límites del conocimiento disciplinario. Pero desde dentro, ella provee evidencia del hecho de que, después de un muy largo periodo, el conocimiento disciplinario ha alcanzado sus propias limitaciones, llevando a consecuencias serias no sólo para la ciencia, sino también para la vida cultural y social" (Nicolescu, 1996, 5).

Para una mejor comprensión del conocimiento transdisciplinar, veamos como lo hemos hecho anteriormente, como se podría caracterizar éste desde el ámbito de la investigación apreciando allí mismo sus diferencias.

Mientras que la investigación disciplinaria se refiere en la mayoría de los casos a un único nivel de realidad, y de hecho en la mayoría de ellos a tan sólo fragmentos de un único nivel de realidad, la investigación tansdisciplinaria se refiere a la dinámica generada por la acción de varios niveles de realidad a la vez.

Mientras las otras formas de investigación no superan el marco del paradigma disciplinar, la transdisciplinariedad busca la comprensión del mundo presente, para el cual uno de sus imperativos es la unidad del conocimiento.

En último término lo que distingue y relaciona a un mismo tiempo al conocimiento transdisciplinar de los conocimientos mono, multi, poli, pluridisciplinares o interdisciplinares es, Strictu Sensu, su finalidad: mientras aquellos no van más allá de su pretensión disciplinar, aunque la amplíen, el conocimiento transdisciplinar se interesa en la dinámica de la acción de varios niveles de realidad de cara a la comprensión del mundo presente, que desde luego, es imposible conocer desde la visión disciplinar. Pero, todas las formas de conocimiento hacen parte de un único e indiviso conocimiento humano. Como advierte Nicolescu (1996):

"La disciplinariedad, la pluridisciplinariedad, la interdisciplinariedad y la transdisciplinariedad son cuatro flechas de un sólo y mismo arco: el del conocimiento".

Sin embargo, la transdisciplinariedad es la apuesta por comprender la realidad que somos y nos constituye, cuando han sido puestos en paréntesis las barreras demarcatorias de las disciplinas y cuando la realidad ya no es vista como un "objeto" que está al frente de un sujeto y que se puede conocer de manera determinista.

Adicionalmente, desde el enfoque transdisciplinar, desde la perspectiva metodológica que ha desarrollado Nicolescu, el investigador puede desarrollar un acervo de capacidades policompetentes y es capaz de derivar hacia una nueva visión de la realidad. En la actualidad estamos viviendo un cambio epistemológico que se orienta hacia un conocimiento transdisciplinar, pero todavía no sabemos en dónde terminará. 


\subsection{El estatuto metodológico de la transdiscipli- nariedad}

La segunda gran novedad del conocimiento transdisciplinar, según Nicolescu (1996), es la postulación de unos supuestos teóricos que determinan la metodología transdisciplinar. Sin esta metodología, nos dice Nicolescu, la transdisciplinariedad no pasaría de ser una charlatanería o una moda pasajera. Por ello vamos a detenernos, en lo que sigue, a presentar la novedad de esta metodología transdisciplinar.

Nos dice Nicolescu $(2006,23)^{3}$ :

"Después de muchos años de investigación, hemos llegado a los siguientes tres axiomas de la metodología de la transdisciplinariedad:

- El axioma ontológico: Existen en la naturaleza $y$ en nuestro conocimiento de la naturaleza, diferentes niveles de realidad y correspondientemente, diferentes niveles de percepción.

- El axioma lógico: El paso de un nivel de realidad a otro es asegurado por la lógica del tercero incluido.

- El axioma epistemológico: La estructura de la totalidad de niveles de realidad y de percepción, es una estructura compleja: cada nivel es lo que es porque todos los niveles existen al mismo tiempo.

Los dos primeros axiomas obtienen su evidencia experimental de la física cuántica, pero van bastante más allá de las ciencias exactas. El último, tiene su fuente no sólo en la física cuántica, sino además en una variedad de otras ciencias exactas y humanas. Los tres han estado, en acuerdo al pensamiento tradicional, presentes en la Tierra desde el inicio de los tiempos".

\subsubsection{Axioma ontológico}

El término realidad, en perspectiva transdisciplinaria, tiene una connotación ontológica y una connotación pragmática. En términos pragmáticos, y dicho de manera negativa, la realidad es todo aquello que se resiste a quedar expresado a través de nuestras experiencias, representaciones, descripciones, imágenes e incluso de nuestras formulaciones matemáticas, pero que se puede conocer. La realidad es lo accesible a nuestro conocimiento aunque haya un nivel de resistencia para ello; lo real, es aquello que nos permanecerá para siempre velado a nuestro conocimiento humano, pero que paradójicamente hace parte constitutiva de lo que somos y podemos conocer aunque ya no de manera representacional. Esta concepción está muy cercana, y de hecho tiene sus similitudes con la concepción de realidad implicada de David Bohm (1988).

Para Nicolescu (1996), un "nivel de realidad" es un conjunto de sistemas que son invariantes, pero sólo bajo ciertas leyes. Así, por ejemplo, las entidades cuánticas, son entidades cuánticas, en tanto que están subordinadas a las leyes cuánticas, que son leyes que aplican de manera específica para el mundo microfísico. Por tanto un nivel de realidad se decide acorde a leyes y cuando se pasa de un nivel de realidad a otro nivel de realidad se presenta una discontinuidad y por tanto hay un rompimiento con las leyes y los conceptos fundamentales aplicables a esos niveles de realidad. Esto es absolutamente novedoso en toda la historia del conocimiento occidental y es al mismo tiempo lo que hace posible la emergencia del conocimiento transdisciplinar.

"Cada nivel de realidad tiene su espaciotiempo asociado, diferente de un nivel al otro. Por ejemplo, el realismo clásico está asociado con la 4-dimensión espaciotiempo (tres dimensiones de espacio y una dimensión de tiempo), mientras que el realismo cuántico se asocia con el espaciotiempo cuyo número de dimensiones es mayor que cuatro. La introducción de los niveles de realidad induce una estructura multidimensional y multirreferencial de la realidad. Un nuevo principio de la relatividad emerge de la coexistencia entre la

3 El carácter axiomático de la metodología de la transdisciplinariedad se construye a contrapelo de los tres axiomas de la ciencia clásica formulados por Galileo Galilei en diálogo sobre los grandes sistemas del mundo: (i) Existen leyes universales de carácter matemático; (ii) Estas leyes pueden ser descubiertas por experimentos científicos y (iii) Tales experimentos pueden ser perfectamente replicados. 
pluralidad compleja y la unidad abierta, en nuestra perspectiva: ningún nivel de realidad constituye un lugar privilegiado desde el cual uno es capaz de comprender a todos los otros niveles de realidad. Un nivel de realidad es lo que es porque todos los demás niveles existen al mismo tiempo. Este principio de la relatividad es lo que origina una nueva perspectiva en la religión, la política, el arte, la educación y la vida social y es cuando nuestra perspectiva del mundo cambia” (Nicolescu, 2006, 25).

\subsubsection{Axioma lógico}

Dicho en términos lógicos, desde el conocimiento transdisciplinar el 'objeto' del conocimiento, no es propiamente hablando ningún 'objeto' que está al frente de un 'sujeto' y que se pueda conocer objetivamente. Lo que propiamente conocemos es la zona de interacción entre los niveles de realidad y los niveles de percepción que podemos tener los 'sujetos' en interacción dinámica con los diversos niveles de realidad. Por esta razón lo trans, es aquello que está entre los campos disciplinares, que se puede acceder a través de los campos disciplinares, pero que va más allá, de los conocimientos adscritos a los campos disciplinares.

La estructura abierta de la unidad de los niveles de realidad consiste en que la topología entre un nivel de realidad y otro es finita, pero el conocimiento que se puede tener de cada nivel puede ser infinito. Dicho de otra manera, la distancia topológica finita, puede contener un número infinito de niveles de realidad. Por esta razón muchas disciplinas pueden estar diciendo diferentes cosas acerca de un mismo nivel de realidad, al mismo tiempo que se puede tener conocimientos en diversos niveles de realidad.

Nicolescu afirma que los diferentes niveles de realidad son accesibles al conocimiento humano gracias a los diferentes niveles de percepción que están potencialmente presentes en nuestro ser. En nuestra percepción, de hecho hay diferentes niveles de percepción, que al igual que los niveles de realidad estarán más o menos distantes de la zona de no-resistencia de la percepción de lo real y que se expresan a través de nuestro conocimiento lingüísticamente mediado de lo real. La zona de no-resistencia perceptiva es la zona que está "más allá" de nuestro nivel de articulación lingüística. Esta zona será la zona de lo irracionalizable, de lo indecible, de lo insondable, es decir del misterio que somos y nos constituye, que aunque no se puede nombrar, desde luego se puede conocer porque hace parte constitutiva de aquella realidad que somos y nos constituye (Corbí, 2007).

La existencia de los diferentes niveles de realidad, como de los diferentes niveles de percepción había sido afirmado por diferentes tradiciones religiosas y espirituales de la humanidad en diferentes épocas y civilizaciones, pero sólo en relación a un nivel de realidad dada la concepción metafísica en la que se empotraban. Haciendo el análisis de aquellas realidades desde hoy, podríamos decir que la zona de no-racionalización, desde otro registro lingüístico, se corresponde con lo que aquella tradiciones llamaban lo sagrado: el "lugar" donde los dioses nos hacen señas; el "lugar" en donde se nos da el conocimiento de la dimensión mística de la existencia; donde podemos tener un conocimiento silencioso de la dimensión absoluta de la realidad.

La unidad entre los niveles de realidad y su zona de no-resistencia complementaria, es lo que en el conocimiento transdisciplinar se llama: el objeto transdisciplinario. La unidad entre los niveles de percepción y su zona de no-resistencia complementaria, es lo que en el conocimiento transdisciplinar se llama: objeto transdisciplinario. Los niveles de percepción son de hecho, niveles de realidad del sujeto, mientras que los niveles de realidad, son de hecho, niveles de realidad del objeto. Un flujo de consciencia que cruza diferentes niveles de percepción, debe corresponderse con el flujo de información que cruza a través de los diferentes niveles de realidad.

Desde esta nueva comprensión, el conocimiento humano no es ni exclusivamente objetivo, entendiendo por tal el conocimiento de la realidad con exclusión del sujeto, ni exclusivamente subjetivo, entendiendo por tal el conocimiento de un sujeto con independencia de la realidad, sino que el conocimiento humano es a un mismo tiempo objetivo-objetivo: objetivamente subjetivo como subjetivamente obje- 
tivo. Esto para el conocimiento científico clásico es simplemente absurdo. Y sin embargo, para nosotros hoy, es lo que hay que pensar, para decirlo heideggerianamente.

Las zonas de no-resistencia del objeto y el sujeto transdisciplinario, deben ser idénticas para que se pueda dar una comunicación entre ellas. Esta identidad o correspondencia entre los niveles de realidad y los niveles de percepción, es lo que se llama en el conocimiento transdisciplinar isomorfismo conceptual. Y es al mismo tiempo, lo que posibilita el papel asignado en el enfoque transdisciplinario al tercero incluido entre el sujeto y el objeto transdisciplinario.

Para ayudarnos a comprender este planteamiento, Nicolescu en muchos de sus escritos nos recuerda el planteamiento Aristotélico que dio origen al enfoque contrario, es decir, el del tercero excluso o excluido, base epistemológica del conocimiento científico occidental.

"La lógica clásica -la lógica aristotélica- se fundamenta en tres axiomas:

- El axioma de identidad: A es A.

- El axioma de no-contradicción: A no es no-A.

- El axioma del tercero excluido: No existe un tercer término $T$ ( $T$ de tercero) que sea a la vez A y no-A.

El conocimiento de la coexistencia del mundo cuántico y del mundo macrofísico y el desarrollo de la física cuántica, nos han llevado, -en el nivel de la teoría y el experimento científico-, a pares de contradictorios mutuamente excluyentes (A y no- $A$ ): onda y corpúsculo, continuidad y discontinuidad, separabilidad y no-separabilidad, causalidad local y causalidad global, simetría y rompimiento de simetría, reversibilidad e irreversibilidad del tiempo... El escándalo intelectual provocado por la mecánica cuántica consiste precisamente en el hecho de que los pares de contradictorios que ésta genera son en realidad mutuamente excluyentes cuando se analizan bajo los filtros interpretativos de la lógica clásica. No obstante, la solución es relativamente simple: uno debe abandonar el tercer axioma de la lógica clásica, imponiendo a la exclusión, la inclusión del tercero (T)” (Nicolescu, 2006, 15)
En la lógica aristotélica, entre un ente "A" y un ente "B" no se da ningún tipo de relación. No hay ningún término o espacio intermedio que los una. Por ello, en la lógica aristotélica como en la ciencia occidental que se encabalga sobre aquella, en el conocimiento humano hay tres términos claramente diferenciados: A, no-A y un tercero excluido. Aristóteles fue el primero en formalizar un sistema lógico proposicional de tipo lineal y binario que se sostenía con el axioma del tercero excluido.

A diferencia de Aristóteles, el físico Stéphane Lupasco desarrollo a mediados del siglo pasado una lógica formal, matematizable, no-contradictoria y multivalente de tres valores: $\mathrm{A}$, no-A y $\mathrm{T}$, que supera el principio aristotélico del "tercero excluido" al introducir el principio lógico del "tercero incluido" (Lupasco, 1951; Finkenthal, 1998). El término T esta al mismo tiempo en A y no-A y es comprensible introduciendo la noción de niveles de realidad entre los cuales existen niveles no-resistentes, es decir, no-nombrables a través de palabras o categorías, que son las nociones utilizadas para referirnos a las cosas.

Occidente con la invención de la escritura, dio carácter de verdad a la representación lingüística de la realidad, en un sólo nivel de realidad, aunque en la mayoría de los casos no se refería a un nivel, sino de un fragmento de un único nivel de realidad asumido como La realidad sin más. En este sentido el conocimiento filosófico aristotélico y el conocimiento científico clásico subvaloraron, cuando no desecharon, todo aquello que no fuera representable lingüísticamente. Con el conocimiento científico experimental -que se inicia en el siglo XVI pero que tiene su culminación en el siglo XIX- la comprensión lingüísticamente mediada de la realidad, se convierte en la comprensión matematizada de la realidad y con ello, el lenguaje matemático o mejor el lenguaje lógicomatemático se convirtió en el lenguaje más idóneo para hacer una representación racional y objetiva de la realidad, de ahí que el lenguaje de la ciencia clásica hasta nuestros días sea el lenguaje matemático. Conocer en sentido moderno el término, es hacer un proceso de matematización de la realidad.

Nicolescu (2006) apropiándose de la lógica de Lupasco y las matemáticas de Gödel postulan la lógica 
del tercero incluido y mediante ésta pone en circulación los niveles de la realidad -no tenidos en cuenta por Lupasco-, y los relaciona con los niveles de percepción sin tener que asumir por ello contradicciones lógicas. Desde entonces, el principio de nocontradicción (tercero excluido) es superado por el principio del tercero incluido para la comprensión lógica de la realidad. Esto también es absolutamente novedoso en toda la historia del conocimiento occidental y es al mismo tiempo lo que hace posible la emergencia del conocimiento transdisciplinar (Nicolescu, 1998a; 1998b; 2000).

Con la introducción del tercero incluido, se pasa de la comprensión binaria sujeto/objeto del realismo clásico a una comprensión ternaria para el conocimiento en donde el sujeto transdisciplinario-tercero incluido-objeto transdisciplinario son los constituyentes lógicos para una visión adecuada del conocimiento humano. El objeto transdisciplinario y sus niveles de realidad, el sujeto transdisciplinario y sus niveles de percepción y las zonas de no-resistencia complementarias, es decir, el tercero incluido entre el objeto transdisciplinario y el sujeto transdisciplinario, constituyen las características lógicas del nuevo enfoque transdisciplinario para el conocimiento de la realidad.

\subsubsection{Axioma epistemológico o de complejidad}

Con este axioma volvemos al comienzo de nuestro artículo y al meollo mismo del conocimiento transdisciplinario. Recordemos que el conocimiento transdisciplinario se da entre, a través y más allá de las disciplinas. Pero, ¿qué puede significar este "más allá" en este momento de la exposición? El más allá, nos relaciona con la finalidad última del conocimiento transdisciplinar: la comprensión del mundo actual, cuyo imperativo fundamental es la unidad del conocimiento. La unidad y la comprensión del mundo actual no pasan a través de una teoría, sino de una nueva visión del mundo y de la racionalidad humana que involucra los niveles de realidad, los niveles de percepción y las relaciones isomórficas entre ambas por medio del tercero incluido. De esta manera el conocimiento transdisciplinario nos permite ir más allá de las disciplinas para involucrar la realidad en toda su posibilidad de ser:
"El modelo transdisciplinario nos permite definir tres tipos de significado:

- Significado horizontal. Por ejemplo, interconexiones a un solo nivel de realidad. Esto es lo que la mayoría de las disciplinas académicas hacen.

- Significado vertical. Por ejemplo, conexiones involucrando varios niveles de realidad. Esto es lo que la poesía, el arte o la física cuántica hacen, y

- Significado del significado. Por ejemplo, interconexiones involucrando toda la realidad -el sujeto, el objeto y el tercero escondido-.

Este es el objetivo último de la investigación transdisciplinar, cuyo eje fundamental es el diálogo entre ciencia y espiritualidad" (Nicolescu, 2006, 124).

Esto último puede parecer sumamente extraño: el diálogo entre ciencia y espiritualidad. Pero, no lo es, si tenemos en cuenta que la comprensión del mundo actual no sería posible si el conocimiento no va más allá de la eficacia por la eficacia, es decir, si no va más allá del modelo representacional de la racionalidad clásica que nos dejo encerrados en un concepto restringido de racionalidad y que dividió peligrosa y arbitrariamente la cultura científica de la cultura humanística.

La nueva racionalidad, es nueva no sólo por su alcance: la comprensión del mundo, sino también por la unidad del conocimiento científico y no-científico. En este sentido, el conocimiento transdisciplinar al igual que la espiritualidad, involucran dentro del conocimiento humano los niveles de realidad, los niveles de percepción y la zona de no-resistencia del tercero incluido. El modelo transdisciplinar al cruzar los tres términos del conocimiento es un conocimiento de la complejidad que somos y nos constituye.

\section{Pensamiento complejo y conocimiento transdisciplinar. Estrategias cognosciti- vas de nueva racionalidad}

La transdisciplinariedad es la forma de conocer la complejidad que somos y nos constituye; es la mejor estrategia cognoscitiva para poner en circulación el 
pensamiento complejo capaz de complejizar la comprensión disciplinar del mundo actual y de reintroducir al cognoscente en todo proceso de conocimiento; el conocimiento transdisciplinar como el pensamiento complejo centran su atención en la comprensión multidimensional y multirreferencial de la realidad y hacen posible un "conocimiento del conocimiento" que es a su vez la clave de bóveda de la epistemología de la complejidad; pensamiento complejo y conocimiento transdisciplinar levantan su vuelo en las postrimerías del siglo XXI, para ayudarnos a buscar la unidad del conocimiento fragmentado en disciplinas y para afrontar desde una nueva racionalidad el reto de la supervivencia planetaria.

\section{Referencia}

Atlan, H. (1990) Entre el cristal y el humo, Madrid: Editorial Debate. Atlan, H. (1991). Con razón o sin ella. Intercrítica de la ciencia y el mito, Barcelona: Editorial Tusquets.

Beck, U. (2006) La sociedad del riesgo, Editorial Paidós, Barcelona.

Capra, F. (1998) La trama de la vida. Una nueva perspectiva de los sistemas vivos. Barcelona, Anagrama.

Capra, F. (2002), Las conexiones ocultas. Implicaciones sociales, medioambientales y económicas y biológicas de una nueva visión del mundo. Barcelona: Editorial Anagrama.

Bohm, D. (1988) La totalidad y el orden implicado. Barcelona: Editorial Kairós.

Corbí, M. (2007) Hacia una espiritualidad laica. Sin creencias, sin religiones, sin dioses. Barcelona: Editorial Herder.

Chew, G. (1968) “¿Bootstrap: A scientific idea?”. En: Science, (161):62-765.

Finkenthal, M. (1998) Rethinking Logic: Lupasco, Nishida and Matte Blanco. Bulletin Interactif du Centre International de Recherches et Études transdisciplinaires. Disponible en: http:// perso.club-internet.fr/nicol/ciret/

Foerster, H. (1962) Principles of self-organization. New York, Pergamon Press. Sistémica elemental. Desde un punto de vista superior. Medellín: Fondo Editorial Universidad EAFIT.

Fox Keller, E. (1995) La paradoja de la subjetividad científica, En: Fried Schnitman, Dora, Nuevos paradigmas, cultura y subjetividad, Barcelona: Editorial Paidós: 143-181.

Gómez, R. \& Jiménez, J. (2003) De los principios del pensamiento complejo, En: Manual de iniciación pedagógica al pensamiento complejo, Quito: ICFES-UNESCO-Corporación Complexus: 190-195.

Gibbons, M. et al (1994) The New Production of Knowledge -The Dynamics of Science and Research in Contemporary Societies: Sage, Londres.

Heidegger, M. (2003) Aportes a la filosofía. Acerca del evento. Buenos Aires: Editorial Biblos-Almagesto.

Heidegger, M. (2007) Sobre el comienzo. Buenos Aires: Editorial Biblos-Almagesto.

Henagulph, Sed, Three pillars of transdisciplinarity. Disponible en: http://www.goodshare.org/pillars.htm.
Illich, I. (2006, 2008) Obras reunidas I y000000 II. México: Fondo de Cultura Económica.

Mittelstrass, J. et al (2001) On transdisciplinarity. En: Science and the future of mankind, Ciudad del Vaticano: 495-500.

Locke, J. (1982) Ensayo sobre el entendimiento humano, Madrid: Aguilar.

Lupasco, S. (1951) Le principe d'antagonisme et la logique de l'énergie. Prolégomènes à une science de la contradiction Paris: Hermann \& Co.

Martínez, M. (2003) Transdisciplinariedad un enfoque para la complejidad del mundo, En: Revista Visión docente con-ciencia, No. 1 Julio. Disponible en: http://www.concienciactiva.org

Maturana, H. \& Varela F. (1990) El árbol del conocimiento. Las bases biológicas del conocimiento. Madrid: Debate.

Morin, E. (1983) El método I: La naturaleza de la naturaleza. Madrid: Ediciones Cátedra.

Morin, E. (1984) Ciencia con conciencia. Barcelona: Editorial Anthropos.

Morin, E. (1984b) Por el pensamiento complejo. En: Ciencia con consciencia. Barcelona: Editorial Anthropos: 293-368.

Morin, E. (1984a) La antigua y nueva transdisciplinariedad, En: Ciencia con conciencia, Barcelona: Editorial Anthropos: 311-317.

Morin, E. (1986) El método II: La vida de la vida. Madrid: Ediciones Cátedra.

Morin, E. (1988) El Método III: El conocimiento del conocimiento. Madrid: Ediciones Cátedra.

Morin, E. (1991) El pensamiento ecologizado En: Gazeta de Antropología No 12. Disponible en: http://www.ugr.es/ pwlac/ G12 01Edgar Morin.html

Morin, E. (1992) El Método IV: Las ideas. Su hábitat, su vida, sus costumbres, su organización. Madrid: Ediciones Cátedra.

Morin, E. (1993a) Tierra patria. Barcelona: Editorial Kairós.

Morin, E. (1994) Introducción al pensamiento complejo. Barcelona: Editorial Gedisa.

Morin, E. (1994) Epistemología de la complejidad. En: Introducción al pensamiento complejo. Barcelona: Editorial Gedisa: 135-164

Morin, E. (1996a) Entrevista en París con Edgar Morin: el pensamiento complejo contra el pensamiento único, En: Revista de sociología y política, "nueva época", universidad Iberoamericana, (8):2-10.

Morin, E. (1996b) Mis demonios. Barcelona: Editorial Kairós.

Morin, E. (1997) La necesidad de un pensamiento complejo. En: Sergio González Moena, (Comp.) Pensamiento complejo. En torno a Edgar Morin, América Latina y los procesos educativos: 13-22. Bogotá: Editorial Magisterio,

Morin, E. (1998) Articular los saberes. ¿Qué saberes enseñar en las escuelas? Buenos Aires: Ediciones universidad del Salvador.

Morin, E. (2001) La cabeza bien puesta. Repensar la reformareformar el pensamiento. Buenos Aires: Ediciones Nueva Visión.

Morin, E. (2001a) Inter-pluri-transdisciplinariedad. En: La cabeza bien puesta. Repensar la reforma-reformar el pensamiento, Buenos Aires: Ediciones Nueva Visión: 115-128.

Morin, E, (2001b) Los siete saberes necesarios para la educación del futuro. Bogotá: UNESCO-Editorial Magisterio.

Morin, E. (2003) El Método V: La humanidad de la humanidad. La identidad humana. Madrid: Ediciones Cátedra.

Morin, E. (2005) Epistemología de la complejidad. En: Solana Ruiz J. Con Edgar Morin, por un pensamiento complejo. Implicaciones interdisciplinarias. Madrid: Universidad Internacional de Andalucía-Ediciones Akál: 27-52.

Morin, E. (2006) El Método VI: Ética. Madrid: Ediciones Cátedra. 
Morin, E. (2010) Complejidad restringida, complejidad general. En: Revista estudios, VIII, (93): 81-135.

Morin, E. (2003b) Educar en la era planetaria. Barcelona: Gedisa.

Morin, E. (2003d) ¿Sociedad-mundo o imperio-mundo? Más allá de la globalización y el desarrollo. En: Gazeta de antropología, (19): 10-23.

Morin, E., Roger, E. \& Motta, R. (2003) Los desafíos de la era planetaria (El posible despertar de una sociedad-mundo), En: Educar en la era planetaria. Barcelona: Gedisa.

Nicolescu, B. (2006) La transdisciplinariedad. Manifiesto, Mónaco: Editions du Rocher. Disponible en: http://basarab.nicolescu. perso.sfr.fr/ciret/espagnol/visiones.htm

Nicolescu, B. (1997) Projeto CIRET-UNESCO: Evolução transdisciplinar da Universidade (síntese do documento). Disponible en: http://basarab.nicolescu.perso.sfr.fr/ciret/locarno/locapor4.htm

Nicolescu, B. (1998a) Aspectos godelianos de la naturaleza y el conocimiento. Disponible en: http://www.cetrans.com.br/novo/ textos/complexidade-e-transdisciplinaridade.pdf

Nicolescu, B. (1998b) El tercero incluido. De la física cuántica a la ontología, Centre International de Investigaciones y estudios Transdisciplinares. Disponible en: http://perso.club-internet. $\mathrm{fr} /$ nicol/ciret/ - 24 novembre

Nicolescu, B. (1999) A Evolução Transdisciplinar a Universidade Condição para o Desenvolvimento Sustentável. En: CIRET, Boletín Encuentros transdisciplinarios, 18.

Nicolescu, B. (2000) Transdisciplinariedad y la complejidad: los niveles de la realidad como fuente de indeterminación: Disponible en: basarab.nicolescu.perso.sfr.fr/ciret/bulletin/b15/b15c4.htm

Nicolescu, B. (2002) Nous, la particule et le monde. París: Éditions du Rocher.

Nicolescu, B. (2006) Transdiciplinariedad: pasado, presente y futuro. Primer parte. En: Revista Visión docente con-ciencia, (31):1531. Disponible en: http://www.ceuarkos.com/Vision docente/ revista31/t3.htm. Segunda parte. En: Revista Visión Docente Con-Ciencia, (32):14-33. Disponible en: http://www.ceuarkos. com/Vision docente/revista32/t4.htm

Nicolescu, B. \& Morin, E. (1994) De fritas Lima, Carta de la transdisciplinariedad. Convento de Arrábida, Portugal. Disponible en: http://perso.club-internet.fr/nicol/ciret/

Nowotny, H. (2006) El potential de la transdisciplinariedad. Disponible en: http://www.interdisciplines.org/interdisciplinaritypapers/5.
Osorio, S. N. (2003) Aproximaciones a un nuevo paradigma en el pensamiento científico. En: Manual de iniciación pedagógica al pensamiento complejo. UNESCO-ICFES-Corporación Complexus. Quito: Ediciones jurídicas Gustavo Ibáñez: 59-94.

Osorio, S. N. (2008a) La emergencia de una nueva racionalidad, En: Bioética y pensamiento complejo I: Un puente en construcción. Bogotá: Prontoprinter Ltda-UMNG: 19-55.

Osorio, S. N. (2008b) El desafío de la complejidad, En: Bioética y pensamiento complejo II: Estrategias para enfrentar el desafío planetario. Bogotá: Archel publicidad-UMNG: 24-44.

Osorio, S. N. (2009a) De la "Teoría crítica de la sociedad" a la "paradigmatología" de Edgar Morin. En: Maldonado Castañeda, Carlos Eduardo (Ed.). Complejidad: revolución científica y teoría: 145-173.

Osorio, S. N. (2010b) Camino hacia la transdisciplinariedad. La paradigmatología en Edgar Morin. En: Pensar desde la educación superior. Una reflexión transdisciplinar. Bogotá: Alvi Impresores-UMNG: 142-166.

Pascal, B. (1973) Pensamientos I. Buenos Aires: Biblioteca de Iniciación Filosófica Aguilar.

Piaget, J. (1972) La epistemología de las relaciones interdisciplinares. En: Léo Apostel et al. 1972.

Potter, Van R. (1971) Bioethics, bridge to the future, Englewood Cliffs, Prentice Hall, N.Y. (1998). Global Bioethics: building on the Leopold Legacy. Michigan State University Press, East Lansing.

Prigogine, I. \& Stengers I. (1987) La nueva alianza. Metamorfosis de la ciencia, Madrid: Alianza.

Richard, N. (1998) Antidisciplina, transdisciplina y redisciplinamientos del saber. En: Revista de Estudios Sociales, (1):118-123.

Snow, C. (1980) Las dos culturas. Ensayos científicos. Ciencia y desarrollo, México.

Solana, J. L. (2001) Epistemología de la complejidad y teoría de la organización. En: Antropología y complejidad humana. La antropología compleja de Edgar Morin, Granada: Editorial Comares:165-223.

Sotolongo, P. \& Delgado, C. (2006) La revolución contemporánea del saber y la complejidad social: Hacia unas ciencias sociales de nuevo tipo. Disponible en: http://bibliotecavirtual.clacso. org.ar/ar/libros/campus/soto/soto.html

Von Neumann, J. (2004) Theory of selt-reproducing automata. En: Illinois University, 1966 -Theory games and economic behavior. Princeton University Press. 